\title{
Erratum to: Sarcopenia in Patients with Chronic Liver Disease: Can It Be Altered by Diet and Exercise?
}

\author{
Matthew R. Kappus ${ }^{1} \cdot$ Mardeli Saire Mendoza $^{2} \cdot$ Douglas Nguyen $^{3} \cdot$ Valentina Medici $^{4}$. \\ Stephen A. McClave ${ }^{5}$
}

Published online: 19 September 2016

(C) Springer Science+Business Media New York 2016

Erratum to: Curr Gastroenterol Rep (2016) 18: 43

Doi 10.1007/s11894-016-0516-y

The original version of this article unfortunately contained a mistake. The surname of the second author was incorrectly listed as Mendoza, when it is actually Saire Mendoza. The correct information is as shown above.

The online version of the original article can be found at doi:10.1007 /s11894-016-0516-y.

Matthew R. Kappus

matthew.kappus@duke.edu

1 Department of Medicine, Duke University Medical Center, DUMS 03142, Orange Zone, Durham, NC 27710, USA

2 Department of Medicine, Ochsner Clinic, New Orleans, LA, USA

3 Department of Medicine, College of Medicine, University of California-Irvine, Irvine, CA, USA

4 Department of Medicine, University of California-Davis, Davis, CA, USA

5 Department of Medicine, School of Medicine, University of Louisville, Louisville, KY, USA 